\title{
Capitalismo tardío y territorio. Imaginarios y contradicciones en la Patagonia chilena ${ }^{1}$
}

PATRICIO MEDINA HERNÁNDEZ

> Escuela de Psicología Pontificia Universidad Católica de Valparaíso

\author{
JUAN CARLOS RODRÍGUEZ TORRENT \\ > Escuela de Diseño Universidad de Valparaíso
}

SONIA REYES HERRERA

> Instituto de Sociología Universidad de Valparaíso

\author{
Universidad de Valparaíso \\ Facultad de Arquitectura \\ Revista Márgenes \\ Espacio Arte Sociedad \\ Capitalismo tardío y territorio. Imaginarios y contradicciones en la Patagonia chilena \\ Diciembre 2013 Vol. 10 № 13 \\ Páginas 91 a 102 \\ ISSN elec. 0719-4463 \\ ISSN imp. 0718-4034 \\ Recepción: Agosto 2013 \\ Aceptación: Diciembre 2013
}

\section{RESUMEN}

La Patagonia, uno de los últimos lugares donde quedan tierras vírgenes, un lugar remoto, con servicios deficientes, donde se posan diversos imaginarios territoriales. Se le percibe como un refugio natural frente al colapso planetario y la degradación ambiental, por lo que se proyecta como antítesis de la vida cotidiana urbana, así como un lugar de interés para el capital transnacional por la posibilidad de desarrollar emprendimientos energéticos, mineros y acuícolas. Este artículo tiene como objetivo analizar, a través de registros etnográficos y de información secundaria, las narrativas que diversos actores sociales configuran en y sobre la Patagonia, durante el proceso de expansión del capitalismo tardío, en un territorio de frontera.

PALABRAS CLAVE

Patagonia, territorio, capitalismo tardío, imaginario

Late capitalism and territory. Imageries and contradictions in the Chilean Patagonia

ABSTRACT

Patagonia: among the few remaining virgin regions on earth, sparkled with scarcely populated settlements, each loaded with local imageries, away from proper public services. Southernmost territories in the wilderness that stand as a remote refuge from the ecological degradation typical of the densely populated urban centers; territories that lend themselves to innovative energy sources, friendly, small scale fisheries, agriculture, stockbreeding and, yes, even mining. This article analizes etnographic primary and secondary data conveyed in the voices on and about Patagonia by its various social actors, amidst the process of carrying across the late capitalist expansion through this, so far, unexposed frontier.

KEYWORDS

Patagonia, territory, late capitalism, imageries

\section{Capitalisme tardif et territoire. Imaginaires et contradictions dans la Patagonie chilienne \\ RÉSUMÉ}

La Patagonie, un des derniers endroits où nous trouvons des terres vierges, un lieu éloigné, avec des services de mauvaise qualité, où se déploient plusieurs imaginaires territoriaux. Elle est perçue comme un refuge naturel contre l'effondrement planétaire et la dégradation de l'environnement, donc elle se présente comme l'antithèse de la vie quotidienne urbaine, mais aussi comme un lieu d'intérêt pour le capital transnational dû à la possibilité de développer des entreprises énergétiques, minières et d'aquaculture. Cet article vise à analyser, à travers des cadastres ethnographiques et des informations secondaires, les récits que configurent divers acteurs sociaux dans et sur la Patagonie, au cours du processus d'expansion du capitalisme tardif, dans un territoire frontalier.

MOTS CLÉS

Patagonie, territoire, imaginaire, capitalisme tardif 


\section{INTRODUCCIÓN}

En la Patagonia han convergido históricamente y en la actualidad múltiples actores e intereses, con pesos específicos e influencias distintas que ayudan a su reconfiguración simbólica y territorial: Estado, privados, inversores, poblaciones locales y grupos ambientalistas; además de turistas y migrantes que buscan refugio y se establecen deseando un cambio de estilo de vida. Sostenemos que el territorio patagónico se complejiza en sus relaciones conforme a los imaginarios que le recorren y a los atributos que se destaquen. Por un lado, constituye un lugar único desde el punto de vista de sus características paisajísticas, su biodiversidad, su aislamiento y escasa demografía; y, por otro, porque cuenta con reservas minerales, madereras, acuíferas y energéticas que lo sitúan en el mapa de interés de la economía global.

Existe una confrontación ideológica y de percepciones en torno a la compatibilidad entre el residir histórico y los límites del intervenir, entre su presente y su futuro, como una contradicción generada en el marco del desarrollo del capitalismo tardío y su relación con el Estado. La predominancia y hegemonía de uno de los imaginarios simbólicos y materiales, entre el valor de uso y el valor de cambio, entre población y mercado, es escasamente compatible respecto del otro, pero cualquiera que se imponga, de manera parcial o total, conduce a un proceso de reescritura de la anatomía del paisaje y del territorio.

El artículo se ubica en un ámbito general de registro de estructuras conceptuales presentes en el discurso social sobre la Patagonia chilena. Se analiza lo genérico y la diversificación social y espacial que producen en términos narrativos y fácticos, de modo de favorecer una lectura de acciones y relaciones sociales que se configuran. Es parte de un programa de investigación y resultado de un eje de análisis ligado a los imaginarios territoriales. El registro combina entrevistas en profundidad no estructuradas, procesamiento de fuentes secundarias, y trabajo de campo. Éste tiene un acumulado de tres años, en el que se ha entrevistado a: agentes gubernamentales, representantes del poder local, pequeños comerciantes, agentes de turismo, ambientalistas, emprendedores, migrantes, residentes históricos, y a jóvenes y adultos de distintas localidades y lugares intermedios en las provincias de Palena, Aysén y Magallanes en Chile² $^{2}$

\section{LA PATAGONIA Y EL ESTADO NACIONAL}

Geográficamente, la Patagonia es el espacio binacional de Chile y Argentina de aproximadamente un millón de kilómetros cuadrados del Cono Sur de América, en el cual existe una gran biodiversidad, grandes fuentes de recursos aún no explorados y otros, no explotados. Por el lado argentino, incluye a las provincias de Neuquén, Río Negro, Chubut, Santa Cruz y Tierra del Fuego; por el chileno, a la provincia de Palena $\left(15.303 \mathrm{kms}^{2}\right)$ y las regiones de Aysén $\left(107.449,4 \mathrm{kms}^{2}\right)$ y Magallanes $\left(126.945,4 \mathrm{kms}^{2}\right)^{3}$.

Contiene la parte sur de la Cordillera de los Andes, con las alturas del Monte Fitz Roy o Chaltén, los Campos de Hielo Norte y Sur, y grandes glaciares; además, de caudalosos ríos que fluyen de manera libre, lagos, fiordos, el Canal Beagle, el Estrecho de Magallanes, costas en el Pacífico y Atlántico, islas, Tierra del Fuego, pampa y desierto, la tundra, bosques, flora y fauna endémica.

En términos demográficos, el estimado poblacional de acuerdo al censo del año 2012 del Instituto Nacional de Estadística de Chile (INE), corresponde a la provincia de Palena 16.268 habitantes; región de Aysén 98.414 habitantes y región de Magallanes 158.987 habitantes ${ }^{4}$.
Etnológicamente, estamos en un territorio diezmado por las campañas militares, evangelizadoras y empresariales, que en incursiones genocidas han exterminado, minimizado y desterrado a las poblaciones originarias en los últimos doscientos años. Grupos étnicos como mapuche, tehuelche, selknam, yámanas, alacaluf, chonos, kaweskar tuvieron distinta suerte (Borrero, 2005). Las poblaciones de ambos lados de la cordillera han tenido una vida bastante autónoma y autogestionada, circulando históricamente entre una y otra nación con escasa y tardía presencia y respuesta del Estado ${ }^{5}$, por lo que las redes alimentarias, de educación, salud, trabajo y familia se han dispuesto y configurado en un ir y venir durante décadas sin trámites aduaneros, permaneciendo por sobre la fijación de los límites administrativos ${ }^{6}$. La línea divisoria fue por más de un siglo una ficción. Muchos colonos no tuvieron una nacionalidad definida por décadas, ni formalizaron en el pasado afinidad alguna con los Estados, por lo que las fronteras no han operado como impedimento, sino que hasta el día de hoy, han sido espacios sociales de gran dinamismo y alta complejidad (Bandieri, 2011:15). Esto ha permitido que las comunidades sean más colaborativas que antagónicas.

Conforme a lo señalado, uno de los rasgos históricos que proyecta la Patagonia chilena son las condiciones en las que se realiza el proceso de ocupación territorial, ya que no hay planificación orgánica de asentamientos por parte del Estado sino que fue espontánea. Entre 1923 y 1930, en el intercambio de epístolas entre Ella Mutti y su hija María Brunswing, avencindada en las tierras australes señalaba: Las mujeres son tan raras aquí que aparecen tan sólo en los atados de los cigarrillos '43', contribución a la cultura patagónica de la casa productora, Piccardo\&Cía (Brunswig de Bamber, 2012:145).

Destaca como iniciativa privada el Frigorífico Bories (1893) en Puerto Natales, en las cercanías de Punta Arenas, propiedad de la Sociedad Explotadora de Tierra del Fuego, la que procesaba, faenaba y refrigeraba miles de ovinos hacia el año 1915 (Martinic, 2001), que constituye una experiencia industrial de capitalismo temprano pero no de asentamiento habitacional planificado para la densificación. A pesar de existir una importante actividad ganadera ovejera a finales del siglo XIX y durante el siglo XX, los asentamientos productivos llamados estancias, si bien desarrollaron la actividad industrial, se caracterizaron por el aislamiento entre unos y otros, y por la ausencia de familias y de política habitacional, lo que ha permitido sostener a Gonzalo Sánchez, que la Patagonia se colonizó con ganado y no con gente (2009:224). Más tarde, debe destacarse en las cercanías Coyhaique el emplazamiento por parte de la Fuerza Aérea de un aeródromo, en Balmaceda (1945), y la presencia de la Empresa Nacional del Petróleo en Punta Arenas (1960), la que desde finales de la década del 50 construyó para obreros y empleados una ciudadela adyacente en Cerro Sombrero.

A diferencia de regiones del norte, como Antofagasta, en el mundo minero del salitre, desde el siglo XIX, encontramos asentamientos privados diseñados para familias, como lo fueron gran parte de las oficinas salitreras y las company town $n^{7}$. En Llanquihue, al norte de la provincia de Palena, la presencia del Estado se concreta a través de una política de intervención territorial con objetivos precisos de asentamiento. Allí, la llegada de colonos alemanes, principalmente a partir de 1852, se realiza con agentes de colonización como Vicente Pérez Rosales y con la activa participación de la embajada de Alemania en Chile. Muestra de ello es la condición urbana y habitacional, ya que los asentamientos fueron réplicas de propuestas de ciudades alemanas.
92 > Revista Márgenes № 13 Vol. 10 > Diciembre 2013: 91-102 Facultad de Arquitectura > Universidad de Valparaíso
$>$ ISSN electrónico 0719-4436 > ISSN impreso 0718-4034 


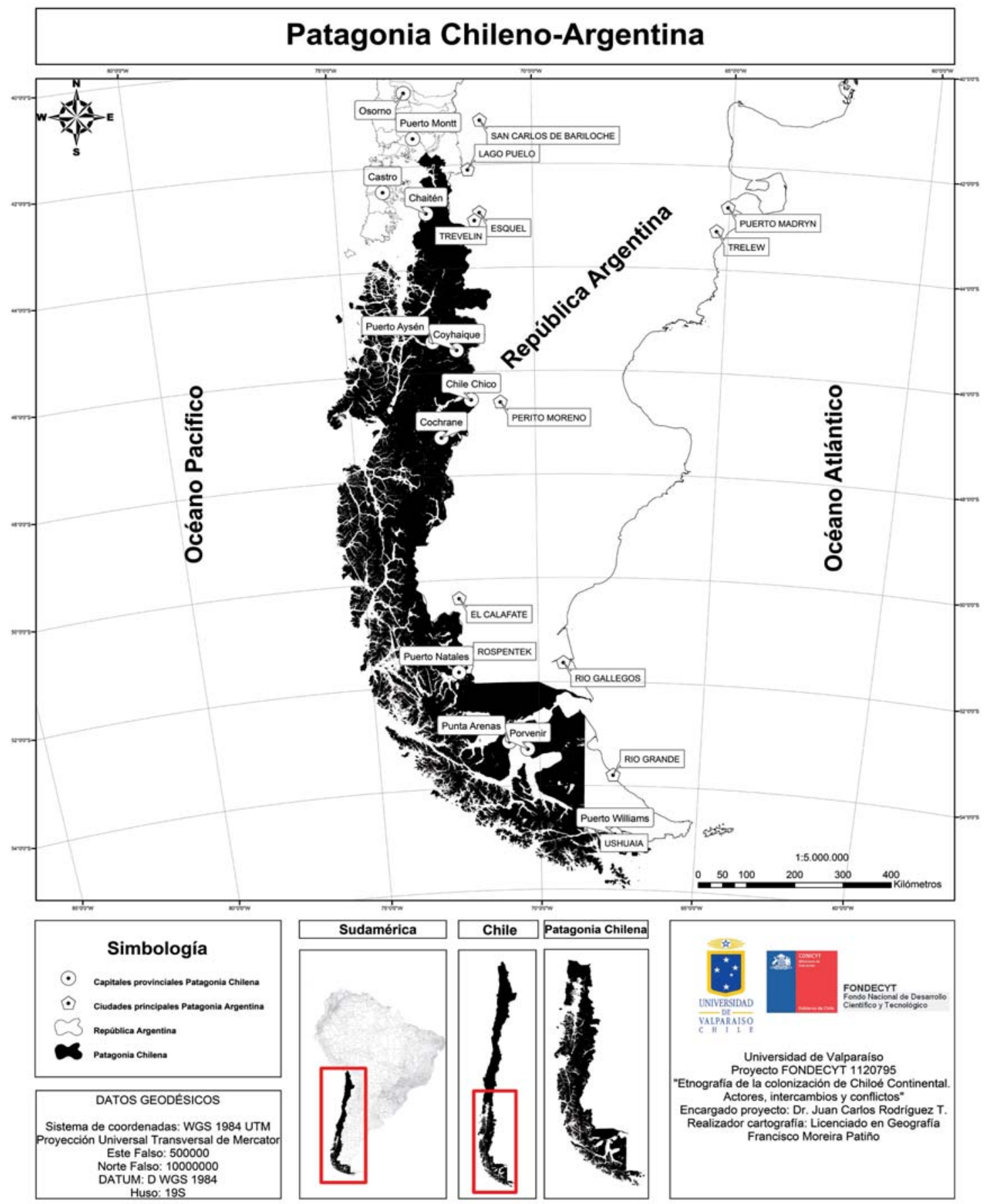

> Figura 1. Cartografía de la Patogonia chileno-argentina. Fuente:autores.

Hasta 1980, Puerto Montt constituía el lugar donde acababa la conectividad y comenzaba la fragmentación de Chile, ya que no existe una red nacional terrestre entre los extremos patagónicos; los aeródromos locales son de baja operatividad y los aeropuertos que conducen a las ciudades de Punta Arenas y Coyhaique son considerados "difíciles" por el viento, el hielo y la nieve. La actual provincia de Palena constituía un lugar impenetrable, lleno de bosques y acantilados, siendo la costa ocupada por pescadores estacionales y extractores de cipreses y alerces que eran transportados a la Isla Grande de Chiloé. En Aysén, lo único que encontraron los pioneros eran selvas y grandes espacios a intervenir por el trabajo manual. Los residentes siempre estuvieron abandonados a su suerte, sin el apoyo de autoridades y sin asesorías. Las tierras de Aysén asignadas a compañías ganaderas inglesas - cuyas administraciones estaban en Valparaíso- a título gratuito o en arriendos por parte del Estado a partir del año 1902, no consideraron colonos; lo que hubo fue esencialmente peones que no tuvieron condiciones para configurar vecindarios. Las compañías de los concesionarios procuraban el negocio para sus accionistas sin marcar presencia física en extensiones de más de 500.000 hectáreas, mientras los pobladores veían en la vastedad de los campos la posibilidad de acceder a tierras y de prosperar a través de la apropiación de aquello que aparecía como infinito y sin dueño. Hubo una o media oveja por hectárea. 
En el relato etnográfico de Annette Laming se anticipaba este cuadro:

Es difícil de imaginar para un europeo que una estancia de 25.000 hectáreas sólo emplee unas doce personas; y sobre todo, que éstas basten perfectamente para el cuidado de los animales y el mantenimiento de las viviendas y los cierres. Sin embargo, su resultado puede apreciarse en los varios millones de pesos que cada año recibe su propietario, beneficio neto que le llega, esté en su dominio o viajando por el mundo (2011: 23).

De acuerdo a estas condiciones, es posible hablar de un proceso autogestionado de ocupación, casi fuera del tiempo y con presencia privada y pocos ecos del Estado, cuyo principal atractor lo constituía la existencia de buenas tierras para el desarrollo de la ganadería como ocurrió principalmente en Palena, Futaleufú, el Valle Simpson o en los alrededores del lago Buenos Aires, entre otros. En Aysén, sin planificación, todo fue a pulso, con traslados de enseres en carretas, por lo que la vida local apuntaba voluntariosamente a la subsistencia; entre 1897 y 1940 se provocaron importantes quemas de los bosques que estorbaban a los nuevos ganaderos, y 2.800.000 hectáreas fueron devastadas con grandes consecuencias para los ecosistemas y el medioambiente (Aleuy, 2012:184-185).

William Hudson (1893), un naturalista, novelista, poeta, y sobre todo gran observador de la flora, la fauna y los modos de vida, quién vivió su infancia en el lado argentino de este territorio, reconoce en Días de ocio en la Patagonia, que su esfuerzo está en tratar de pintar la naturaleza con colores muy reales, por lo que describe la Patagonia como fascinante, a pesar de ser gris y monótona, porque quizá no exista lugar donde se ejerciten más los sentidos. Pero agrega que la misma regularidad ambiental configura un estado de "letargo", "indolencia" e "indiferencia" de la cual cuesta salir, ya que se pierde la preocupación por los asuntos del mundo, la política y las novedades; es imposible activar el cerebro, obligándolo a permanecer inactivo, se renuncia a recibir cartas, telegramas y periódicos, sólo se dedica a tomar café y a los juegos de salón. Se puede sentir, vivir solo y alejado de toda mirada humana, hasta convertirse en otro hombre, sostiene. De modo que el colono tiene por delante un número de trabajos ininterrumpidos y cada día le será más difícil volver a la vida del pasado que alguna vez conoció; su premio será el infaltable alimento y la rústica vivienda para defenderse del calor o el frío. En 1954, la antropóloga Annette Laming, definía la Patagonia como el lugar donde parece no haber tiempo, sino solo espacio. Además agregaba que: Los silencios son más largos que las frases. Todos siguen de pie, indefinidamente, a la espera; a la espera, sin duda, de que el tiempo pase (2011:19).

En el caso de Magallanes hubo una intensa ocupación con los inmigrantes croatas, allí el puerto, como paso obligado de la navegación interoceánica antes de la construcción del Canal de Panamá, permitió el desarrollo de un mundo más cosmopolita y disponer de otras condiciones de territorialización, por lo que hubo caminos que ayudaron al traslado más expedito de bienes muebles, e inclusive cuestiones que pudiesen ser consideradas comparativamente fastuosas (i.e. pianos); aquí, la actividad ganadera en las estancias dejó huellas de identidad, por lo que puede considerarse en sí mismo lo más próximo a un modelo de desarrollo capitalista.

En la década del 50 del siglo pasado, en el centro de Chile se gestaba un proceso de modernización con un fuerte componente industrial y de desarrollo urbano. Consecuencias de este proceso fueron la elevación de los niveles de empleabilidad y consumo, ampliación de coberturas educacionales y sanitarias, lo que inspira una imagen colectiva de país (Larraín; 2001:109). Esta condición, que es una forma de capitalismo organizado, es insuficiente ya que no es incluyente respecto de campesinos y sectores urbanos no organizados (Castells, 2006:41), no logra irradiarse e integrarse territorialmente hacia la zona en cuestión en términos económico productivos y de constitución de una identidad de carácter nacional, salvo en las iniciativas enunciadas más arriba para Punta Arenas. De modo que, entre Puerto Montt por el norte y Punta Arenas por el sur, las condiciones de habitabilidad de los escasos poblados no promovían la llegada de nuevos colonos, ya que el Estado contaba con escaso agenciamiento. Esto generó en la práctica la idea de una frontera interior y del espacio vacío.

La baja ocupación territorial, el aislamiento y lejanía respecto de los centros administrativos y políticos, avalados por las políticas centralistas del Estado, ponen al frente la idea de una frontera interior y un conjunto de cuestiones críticas y estructurantes permanentes del vivir patagónico en relación al agenciamiento del Estado: 1. el infra abastecimiento de los servicios dirigidos a la población; 2. un proceso migratorio intrarregional desde las zonas rurales a los principales centros urbanos de las regiones (Puerto Montt, Coyhaique y Punta Arenas); 3. Ios escasos encadenamientos económicos productivos regionales; 4 . los problemas de soberanía y 5 . la indiferenciación cultural respecto de "lo argentino". El excomandante en Jefe del Ejército Juan Emilio Cheyre, en una entrevista otorgada a la Radio Universidad de Chile (2012), habla de un país invertebrado y de una regionalización en deuda, en la medida que no se ha logrado autonomía local en la Patagonia ni estabilidad demográfica. Si se analiza como continuum, ya en las primeras décadas del siglo pasado estaba presente el mismo fenómeno en la actual región de Aysén: un poblamiento ambiguo y espontáneo con empresas inglesas y con personas provenientes del centro sur de Chile, con largas estadías en Argentina y con fuerte influencia cultural trasandina (Osorio, 2007:24), lo que se ve reforzado por la ausencia de ritos de chilenidad ${ }^{8}$.

Lo señalado evidencia la falta de una política territorial con institucionalidad ad hoc, subsidios e incentivos para que la población se asiente y permanezca en la zona; es manifiesta una condición de frontera, debilitada por la carencia de apoyo del Estado y una mala calidad de vida de la población en términos de acceso a servicios e infraestructuras. Esto tiene como corolario la escasa densidad demográfica desde el sur de Puerto Montt a Tierra del Fuego, de menos de un habitante por kilómetro, lo que nos habla de un país que tiene distintas aceleraciones regionales, así como una distribución de oportunidades sociales y culturales muy desiguales territorialmente.

\section{AISLAMIENTO E IDENTIDAD}

En Puerto Montt comenzaba "otro país", "algo absolutamente distinto"'. Un país impenetrable e invertebrado, de colonos enfrentados por décadas a la nada; una isla, un mundo en gran medida autónomo, donde los grandes páramos hacían que la soledad generara un encierro en sí mismo, hasta configurar un cierto olvido del exterior, una pérdida de contacto con el mapa geopolítico y una prescindencia de lo que acontece en ese "otro país del centro". Se constituye un cosmos, un orden que se define por otras categorías temporo-espaciales como el aislamiento, condiciones climáticas extremas, solidaridad y ayuda mutua entre pobladores, y fuerte vida familiar al interior de los hogares, por una combinatoria de 


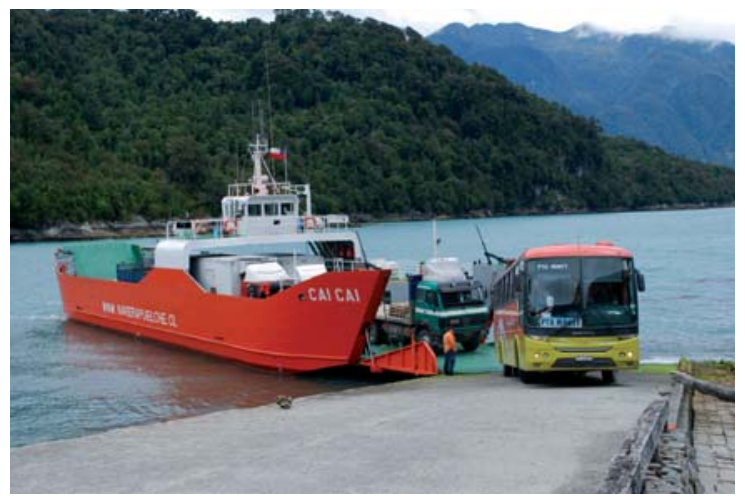

> Figura 2. Conexión bimodal mar - tierra. Fotografía: autores.

escalas en lo empírico, lo institucional y los roles, lo que determina un conjunto diferente de relaciones, reacciones y elecciones frente a las estructuras normativas nacionales. Las condiciones vividas constituyen el germen de la forja de un origen, de la invención de un tipo de vida y de una afiliación que configura autoatribuciones en términos de memoria: pioneros y colonos.

Entrado el siglo XXI, la condición del viejo colono desprovisto en el extenso páramo -expuesta por Hudson-se mantiene; lo mismo, en términos de la descripción que realiza Aleuy para la configuración de la memoria de Aysén en 2012. El diario El Mercurio, en su edición del día 22 de junio de 2013, señala que mientras se discutía en el Congreso Nacional, en Valparaíso, una ley que "podía" autorizar la venta de fármacos en supermercados, a 1.720 kilómetros, en Villa O'Higgins, la comuna más austral de la región de Aysén, sus 680 habitantes no cuentan con farmacia ni consultorio y la ronda médica se realiza cada 15 ó 30 días, sólo si las condiciones climáticas lo permiten. Villa O'Higgins se encuentra a 571 kilómetros de distancia de Coyhaique, el lugar donde puede encontrarse un hospital base para satisfacer las demandas de salud. Se agrega que ninguna empresa los provee regularmente de combustible y sólo un camión municipal recolecta los bidones para cargarlos en Cochrane, a 237 kilómetros. En términos productivos, para vender Ios animales, una barcaza en el lago O'Higgins en el lado chileno -San Martin en el argentino- pasa una vez al año ${ }^{10}$. Además, las regiones de Aysén y Magallanes y la provincia de Palena no son autosuficientes en términos alimentarios. La Patagonia tiene un circuito de comunicaciones precario y problemas independientes que se resuelven localmente, con escasos vínculos con el centro, para algunos "una bolsa que ahoga", “una frontera interior"11. La experiencia de aislamiento geográfico anuncia una amalgama indisoluble entre la vivencia del espacio, el tiempo, las relaciones y la convivencia, pues los sistemas de producción y reproducción de las comunidades rurales y los centros poblados como Punta Arenas y Coyhaique tienen un soporte espacial singular: lejanía, difícil acceso y escaso desplazamiento de sus habitantes. Así, para muchos -y es lo que registramos en el trabajo de campo etnográfico en la provincia de Palena, y en las regiones de Aysén y Magallanes- es el lugar donde las opciones humanas están determinadas en gran medida por la geografía y su paisaje; en este sentido, hay siempre una cuestión sacrificial de renuncia que carga cada hombre y mujer que viven en sus distintos rincones, ya que una ampliación de las expectativas significa abandonar la Patagonia.

La figura de la lejanía y del aislamiento se mantienen dentro de coordenadas que hablan del déficit, de cambios severos, de amenazas y factores de expulsión en términos de salud, educación, trabajo y servicios. Los habitantes oriundos de estas tierras manifiestan preocupación respecto de la pérdida del modo de vida y cultura tradicional de la región, mostrando un especial reconocimiento por la generación de pioneros que abrieron Aysén y Palena a la colonización. Las presiones asociadas a la precariedad de la economía ganadera frente a la fragilidad de los suelos, la migración de la juventud a las ciudades y a otras regiones de Chile buscando oportunidades de estudio y trabajo, junto a la compra de tierras con fines de conservación y turismo por inversores privados nacionales y extranjeros, peticiones para exploración y explotación minera han generado la desaparición paulatina del gaucho y de la familia tradicional patagona, junto con sus vestimentas, música y otras costumbres. También se perciben como amenazados otros aspectos más genéricos de la vida rural y bucólica: la tranquilidad, el ritmo del tiempo en el campo, las relaciones de convivencia con los vecinos. Si bien, en general los entrevistados dan la bienvenida al "progreso" cuando se anuncian inversiones del Estado o la llegada de profesionales, expresan también preocupación y reparos por emprendimientos mineros y por la posible construcción de represas hidroeléctricas, pues la forma de progreso traído por ellas, promete acelerar la pérdida de la vida auténticamente aysenina.

\section{CAPITALISMO TARDÍO Y SACRALIZACIÓN DE LA NATURALEZA}

América Latina ha entrado con fuerza en el imaginario geográfico del capitalismo tardío, señala Gabriela Nouzeilles (2002:12-13), en atención a que en su vastedad se encuentran importantes territorios a los cuales se les confiere el carácter de refugios de lo natural frente al "eclipse radical" del planeta. Entre ellos se encuentran Los Andes, la selva amazónica y las mesetas patagónicas. A partir de esto, una doble lectura ha empezado a configurarse sobre este atributo: 1. la exclusividad de contar con recursos primarios que no es posible disponer en otros lugares como los países centrales y 2. la oferta de oportunidades de una nueva vida, bajo condiciones menos alienadas que las que se pueden encontrar en los centros urbanos. Este carácter bifaz de Sudamérica, en relación al tipo de centralidad que alcanza la naturaleza, constituye una demarcación que reconoce un nuevo capital simbólico asociado a la pureza y a lo místico, un renovado trato con ésta, otra posibilidad para hacer la vida, configurando una importante retórica que se despliega sobre su territorio, más allá de sus contornos geográficos.

Existe una construcción ideológica sobre lo que es posible encontrar, lo cual permite describir, apropiarse y valorar la singularidad del paisaje patagónico, las bondades, adversidades y algunos bienes culturales que le son propios. Esto ocurre bajo el rótulo de la lejanía y el exotismo, junto con el reterritorializar en el mercado los usos, saberes, costumbres y formas de vida tradicionales, emprendiendo viajes temporales y espaciales que remontan a la exploración, a la sorpresa y al desafío de los tempranos pioneros y colonos, constituyendo nuevas formas de consumo cultural dentro de los marcos de reestructuración del capital (García Canclini, 1982). Así, el paisaje es a su vez una realidad física y representación que culturalmente nos hacemos de él; la fisonomía externa y visible de una determinada porción de superficie terrestre y la percepción social e individual que genera: un tangible geográfico y su interpretación intangible (Nogué, 2006:136).

La naturaleza sudamericana y patagónica va también de la mano del turismo. Dentro de la producción simbólica en la economía capitalista tardía, juega un papel relevante en la configuración de los 


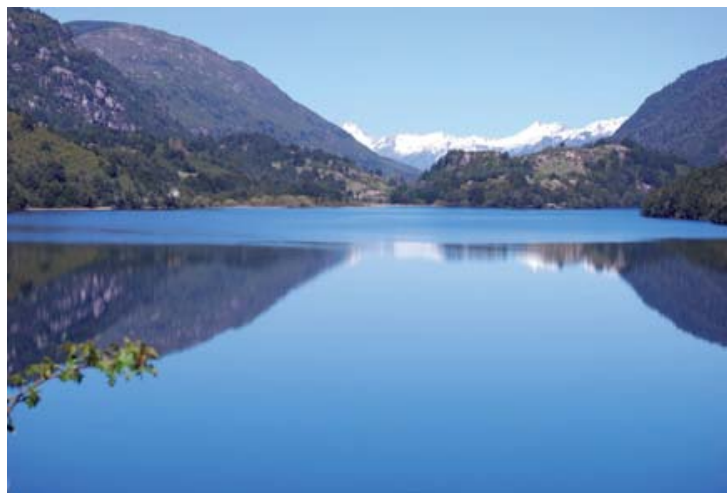

Figura 3. Lago Espejo en Futaleufú, provincia de Palena. Fotografia: autores.

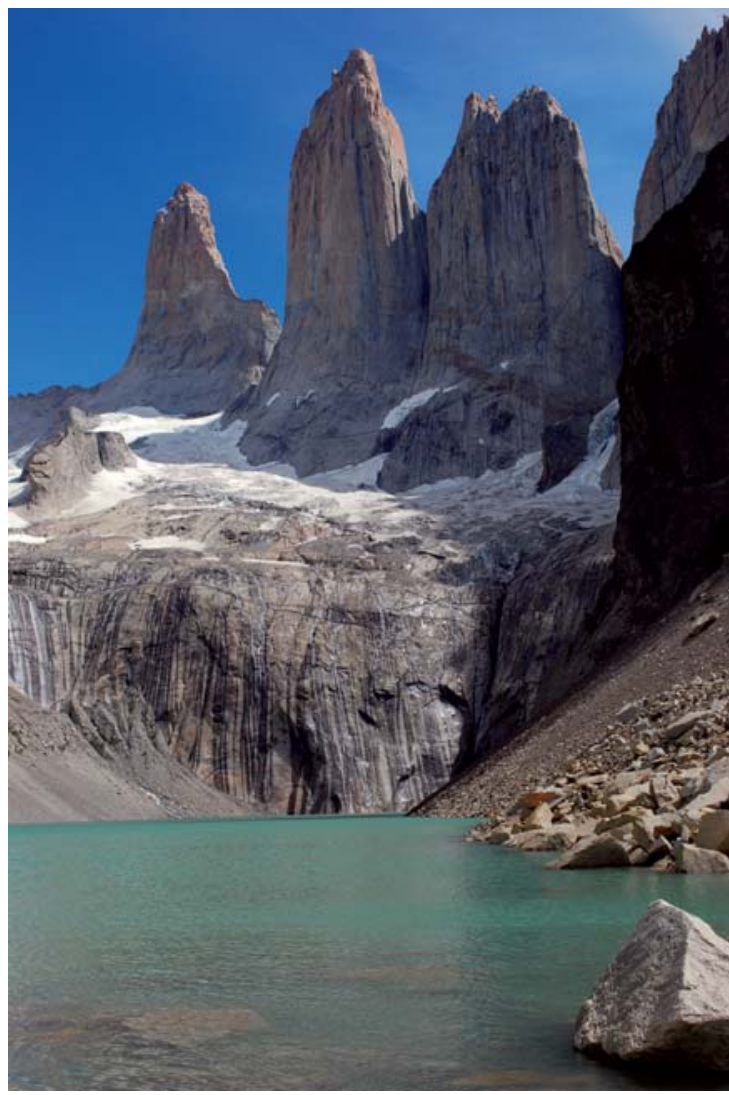

> Figura 4. Torres del Paine. Fotografía: autores.

nuevos negocios y circulación de los capitales por el mundo, teniendo desde los años 80 un crecimiento expansivo. El imaginario geográfico del que hablamos, refiere a un nuevo diseño espacial del capitalismo que conlleva a una organización retórica de lo natural y lo social. Los lugares que reúnen ciertas condiciones escénicas, de suficiente alejamiento, de privacidad y de seguridad, como la Patagonia, entran al mundo de las "ideas y representaciones”, al "mercado y las tarifas", en un proceso de jerarquización y posicionamiento "de ventajas y desventajas". Además de características singulares de "administración, acceso y uso de los recursos", de participación de actores diversos como el Estado, grupos étnicos, poblaciones locales, ONGs, inversores y especuladores, que reconstituyen las identidades locales (Dimitriu, 2002:77-78).

Cuando nos referimos a capitalismo tardío, pensamos que su característica dominante es la mundialización o globalización de la producción y el consumo como proceso desterritorializado y como fuerza expansiva que se reterritorializa. Corresponde a la expresión máxima del consumismo, expresado como perversión del hedonismo inoculado en todas las clases y estratos de la sociedad (Torres, 2013), ya que las esferas que se encontraban fuera de su interés histórico también se anexan. Implica un control y subordinación de la naturaleza, la jerarquización del espacio y el territorio, sólo así alcanzan su verdadera importancia y valorización. En este esquema, por una parte, se produce una simplificación de la complejidad de la vida (i.e. oposición naturaleza-cultura), ya que se vuelve importante sólo la relación costo-beneficio y la tasa de retorno del capital invertido; y, por otra, en los países más pobres, los lineamientos de esta opción operan por sobre el Estado, como una entrega servil al dictum del capital global.

En esta subordinación de la naturaleza, puede esperarse como regla general: una restricción de uso a los territorios, un aumento de la contaminación como externalidad (pasivo ambiental), y un conjunto de normas débiles emanadas del Estado que regulan el accionar de las empresas, inferiores en exigencias a aquellas con las que operan en países de origen, lo que constituye una ventaja comparativa a favor de las empresas y su capital. De este modo, el territorio es una forma específica de relación social y de sujeción.

En un régimen de acumulación flexible como el que vivimos, señala Susan Stonich (1998, 24-25), el recurso natural como bien simbólico correspondería a una "exportación no tradicional" dirigida al mercado. Según esta matriz de negocios, la investigadora registra cómo en América Central, específicamente en Honduras, se integran sinérgicamente los sitios arqueológicos mayas, la historia colonial, el paisaje de las playas y los prístinos arrecifes de coral. La entrada de su singularidad en el mundo de los negocios y de reproducción del capital, asumida como política de Estado, en el fondo implica para los dueños del capital, escasas inversiones fijas, pocos trabajadores y el acceso a beneficios fiscales y exenciones tributarias tanto para la construcción de la infraestructura y los bienes requeridos para implementar el negocio: aeroplanos, yates, vehículos especiales.

La invención del nicho, en su conjunto permite nadar, bucear, pescar, explorar, entre otras actividades “maravillosas”. A partir de este nuevo "producto" se desencadenaron importantes presiones sobre el agua para consumo humano, la contaminación de algunos acuíferos y de las aguas saladas, se desarrollaron desconocidas enfermedades infecciosas en la piel, los ojos y gastrointestinales; asimismo, se produjo la erosión y deforestación debido a la construcción de canchas de golf, de jardines, y una alta polución producto del uso de vehículos (Stonich, 1998).

El caso hondureño, analizado por Susan Stonich, constituye una fórmula de ampliación del capital. Siguiendo la argumentación de la investigadora, observaremos que existe un interés y un mensaje que valoriza la naturaleza y la incorpora al mercado, cuya narración se constituye a través de soportes como la fotografía, el video y el mapa, que promocionan las bondades de productos como Juan Valdez, Chiquita Banana o Starbucks en términos de más sabor, color y menos químicos (Nouzeilles 2002:13). Consumo que, extensivamente puede ser entendido como Patagonia y aire libre, Patagonia y espacio, Patagonia y fuerza del agua, Patagonia y ríos, Patagonia y pesca deportiva, Patagonia y aventura, Patagonia y contemplación, Patagonia y retorno a la naturaleza, Patagonia y libertad, entre muchas otras. 
Estos son soportes de una iconografía de la seducción, que refuerzan una anatomía "verde", una forma "armónica" de ver el mundo, que disfraza y disimula los elementos constitutivos del mercado posmoderno: la mercantilización de la vida cotidiana, el predominio de las industrias culturales y la conversión de las sociedades en espectáculo (Nouzeilles, 2002). Por tanto, diremos que el capitalismo tardío es extremadamente flexible al atender algunos atributos regionales y locales y funcionalizarlos sistémicamente de manera global, aun cuando pueda en apariencia ser opuesto a los propios imaginarios que es capaz de albergar para su reproducción.

Así, la Patagonia también es parte de ese circuito que se ofrece a los sentidos: colores, olores y sonidos del viento, de las aguas y las aves. La Patagonia lejana e inhóspita, se renueva y destaca como el confín del mundo, la finis terrae, la frontera de la civilización, la imagen de parte del globo que se nos guarda en reserva, una suerte de belleza inmaculada, de particularidad estética invaluable. Se le promociona como un espacio de excepción, que genera una polaridad valorativa, ya que es la antítesis de la vida ordinaria, del frenesí urbano consumista, del agobio de las tareas y la escasez de tiempo, por lo que aumenta la imaginación social respecto de lo que contiene.

Como ejemplo, el homónimo Patagonia Inc, promociona en su página web un concepto global de resguardo y preservación del mundo, destacando los principios del reducir, reparar, reutilizar y reciclar; un sentido de la existencia respetando la vida de los demás seres, vida sana, juventud, pureza, aventura y descubrimiento, como formas valóricas que representan el buen vivir y el estar y situarse de otra manera en el mundo (http://www.patagonia.com/us/ common-threads/?In=452).

El paisaje patagónico se convierte en un repositorio de un orden político, económico, axiológico y estético dentro de los marcos del capitalismo tardío. Ha actuado como frontera de contención de procesos industriales, y actualmente entra al mercado global calificando positivamente como región deseable, con una fuerte implicación emocional y afectiva. De tal forma que, su inserción en el mercado global trasciende la frontera geográfica. Ella es frontera de muchos y diferentes significados: frontera de la civilización, frontera espacial, frontera de culturas y visiones de mundo, de etnias, de la historia y de la historicidad del hombre, y sobre todo de la historicidad de lo humano (Souza Martins, 2009:11). En particular, en este territorio se abre una frontera económica tal como ocurrió con la Amazonía en Brasil. La Patagonia, dentro de este esquema se suma al avance del capitalismo tardío, caracterizado por la fuerte inversión extranjera y la escasa regulación del Estado.

La Patagonia, como finis terrae se convierte en una topografía particular, ya que lo importante deja de ser el espacio "en sí, éste se desplaza al orden de la representación, a los distintos modos de tratar de presentarlo; a las geografías y cartografías como intentos por (d)escribir el espacio, no como substancia sino como efecto, no como esencia sino como relación (Huffschmid, 2012:11). Así, lo relevante de este proceso es que no se trata de una síntesis equilibrada de actores, sino que reside en las múltiples dialécticas que provoca y en los lugares productivos discontinuos que genera (Boisier, 2006:150), ya que la vida local continúa conforme a las limitaciones señaladas anteriormente.

De este modo, la naturaleza o el espacio pueden ser concebidos sin límites, pero los territorios habitados y apropiados sí los tienen (Barabás, 2004:148), lo que indica que un territorio dentro de los límites del capitalismo tardío no sólo ofrece lo que pudiésemos llamar recursos escasos, sino también construcciones y cargas simbólicas que ponen límites, al apropiarlos y convertirlos en lugares significativos para la economía de la experiencia. Los rápidos extraordinarios del río Futaleufú para la práctica del kayac y las bajadas en balsa, los alerces milenarios del Parque Pumalín, los reflejos de las montañas y bosques en el lago Espejo, los senderos para el trekking que conducen a los cuernos de las Torres del Paine, muestran estas apropiaciones, porque controlan el sentido de la existencia y reflejan la estructuración cognitiva en relación al entorno en el que se inscriben y orientan las acciones. Se trata de categorizaciones espaciales que configuran un mapa cognitivo territorial (diferenciación de otros grupos), psicosocial (atribuciones internas y externas), temporal (trayectoria y sentido histórico), conductual (prácticas propias), ideológico (principios que rigen la comunidad) y social (características de la estructura).

\section{LA PATAGONIA COMO INTANGIBLE}

La Patagonia, una idea geográfica históricamente asociada a lejanía, emerge como un concepto con un fuerte magnetismo y una impronta peculiar, que entra en el mercado y se constituye en una marca registrada, Patagonia Inc. Decir Patagonia es referirse a un conjunto de significados atribuidos al espacio, a un paraíso verde, a una condición sui generis y exclusiva, a un lugar deseable, algo que aún no entra definitivamente en el derrotero de la corrosión moderna y su imagen es tan potente como decir Ártico, Desierto de Atacama, Himalayas, Sahara, Kalahari, Amazonía, Galápagos. Se trata de lugares que despiertan un imaginario que evoca y transporta a un paisaje y condiciones ambientales particulares que capitalizan una reputación que es más amplia que el mapa cognitivo de las comunidades implicadas. La palabra Patagonia define una condición que activa un imaginario territorial con atributos positivos y características propias; resalta y estimula el vouyerismo del valor de lo natural; y refuerza el deseo y la afiliación de todos aquellos que de una u otra manera se identifican con un paradigma de desarrollo verde y de decrecimiento.

Debido a la sobreexplotación de la imagen de un modo retórico, como iconografía sagrada de la naturaleza, la Patagonia como representación de lo prístino, no violado ni violentado por el hombre ni sus formas de explotación, adquiere un nuevo status, convirtiéndose en un recurso de exportación paradisíaco, que ha sido "descubierto" por el capitalismo tardío y que puede ingresar al mercado. Primero, representado en objetos ajenos, como ropas deportivas, aguas minerales, músicas relajantes y otras; segundo como promoción de estilos de vida o sueños a los que todos pueden acceder, a través del cine, el documental, la literatura y la fotografía y, tercero, los propios viajes de los outdoors promocionados a medida de los expedicionarios más acaudalados, los cuales pueden establecerse temporalmente en lodge y hoteles boutique adecuados según los valores defendidos, donde el peregrino puede realizar el viaje a la naturaleza inmaculada.

Existen asentamientos VIP, como Chaltén en Argentina y lodges en Chile que operan de manera desterritorializada, ocupados por personas de Estados Unidos y Europa que no tienen ninguna vinculación con el territorio horizontal en el que viven los lugareños. Pagan por la exclusividad y por el anonimato, participando del canon de la "economía de la experiencia" que corresponde a "otra forma de conocimiento" (Pine y Gilmor, 1999), la cual tiene que ver con el despertar sensaciones y emociones provistas por la naturaleza y el ritmo la vida local, cruzada por el aislamiento y las pocas tentaciones modernas. 
La experiencia transmite un mensaje de esperanza planetaria, reconceptualizando la naturaleza como un elemento sagrado de la cultura. Rompe así con la división cartesiana cultura-naturaleza y con el esquema dicotómico durkheimiano de lo profano y lo sagrado, reubicando lo sagrado en el mundo secular contemporáneo y al hombre en la primigenia naturaleza de la Patagonia.

De esta manera, el peregrino con sus zapatillas de trekking es un afortunado que ha entrado al lugar sagrado, ha traspasado la frontera de lo cotidiano, de su propio sistema social, se ha transgredido a sí mismo y ha podido vivenciar y comprobar lo real maravilloso de esta experiencia. Sólo le resta la misión de transmitir a otros, de manera testimonial, la veracidad de la grandeza de lo inmaculado, la reflexión introspectiva de la vida y la naturaleza, el sentimiento de lo íntimo, el soliloquio, la pequeñez del individuo, los límites del cuerpo y la convicción vívida de la responsabilidad sobre el ecosistema y su protección.

Para quienes viven la experiencia pasa a ser un territorio sentido, apropiado, interpretado, narrado, imaginado y representado positivamente en distintas partes del mundo. Opera y se inscribe como un gran discurso que se universaliza, que remite a lo físico y a lo emocional; lo único e irrepetible que ofrece es estar en el mundo de otra manera, transmitiendo evocaciones y asociaciones míticas y místicas; unificando virtudes y promocionando un paisaje y un territorio deseables.

La Patagonia provee una fantasía escapista - en términos de Nouzeilles (2002) - al ser concebida como una posibilidad para la construcción de la propia subjetividad, con otras reglas y términos frente al carácter repetitivo y compulsivo del mundo urbano. Tiene un aura singular: en torno a ella existe una iconografía de la seducción, crea una expectativa frente a un nuevo proyecto de vida, despierta una sensibilidad mayor sobre la naturaleza, estremece con su grandeza, anuncia un lugar donde comienza la aventura y la posibilidad de acceder a rincones y parajes únicos. Permite para quienes la recorren estar donde aún no ha llegado nadie o pocos han llegado.

Conforme a esto, las empresas de ecoturismo en la Patagonia tratan de satisfacer el deseo de sus clientes acomodados de escaparse del estrés de la civilización moderna para internarse-durante las vacaciones-dentro de un mundo que se percibe como natural y apacible (Schiwy, 2002:203). El lugar a partir de la actividad ecoturística se convierte en una variación híbrida de mercancía (place commodification), transitando el valor de uso del territorio al valor de cambio (Dimitriu, 2002:81).

\section{LA HUIDA DEL MUNDO O EL REFUGIO DEL ANTROPOCENO}

Lo especial del paisaje patagónico y de sus condiciones no es nuevo. Mítico y legendario ha resultado desde los años sesenta el “paralelo 42" donde se ubica El Bolsón, en Argentina, en el lado oriental de la cordillera; lugar elegido para el asentamiento de una comunidad que lo prefirió como punto de huida de la Guerra Fría, donde los efectos de la radiación derivados de la amenaza nuclear no llegarían. Allí, cargados de energías y de buenas ondas (Sánchez, 2009:30) se instaló una colonia hippie y contracultural para construir una utopía pre-moderna. Los recién llegados, rockeros y alternativos, fueron migrantes motivados por un cambio de estilo de vida, lifestyle migrants, que buscaban una cierta salvación a través de la vida en comunidad, un decrecimiento del consumo y que trataron de hacer frente a los anunciados "problemas ecológicos" y del mundo bipolar. Configuraron un imaginario al vincular el discurso intelectual y científico de la interconexión de los subsistemas naturales con la crítica al capitalismo y sellaron la imagen de una Patagonia-refugio, la que debe ser protegida de la expansión capitalista.

Anunciaron la huida del mundo tecnologizado y de la alienación urbana que estaban presentes en El hombre unidimensional de H. Marcuse (1993), de la estrechez de las posibilidades dentro de las estructuras del capitalismo. Ellos anticiparon lo que a partir de 2002 se ha llamado "período antropoceno" (Crutzen, 2002; Steffen, Crutzen, McNeill, 2007). Este concepto identifica una nueva era planetaria y significa "lo nuevo fabricado por el hombre" (Bybee, 1991), caracterizada por el aumento de población y el volumen de las actividades humanas que han desbaratado todos los sistemas fundamentales para la sustentabilidad de la vida desde los inicios de la revolución industrial, y sus consecuencias en la degradación ambiental, generando una condición de “emergencia planetaria”.

Esta condición ocurre porque los indicadores económicos y de producción han sido considerados sistemáticamente positivos, y los ambientales permanentemente negativos. Este desequilibrio crónico de riesgos que no están localizados sino generalizados, demuestra que lo único cierto es que la actual trayectoria de la actividad humana no es sustentable (Sachs, 2008:87), tiene efectos territoriales, políticos, éticos, estéticos y económicos negativos sobre nuestras vidas (Beck, 1998), y en el caso de Chile, se duda sobre cuánto tiempo más es sostenible una estrategia exportadora de recursos naturales (Solimano, 2012:24).

Como sostiene Bruce Chatwin para esta huida: Imaginé una cabaña con troncos baja, con techo de tejas, calafateada contra las tempestades, con un crepitante fuego de leña en el interior y las paredes cubiertas con los mejores libros: un lugar donde vivir cuando el resto del mundo volara en pedazos (2004:10).

El magnetismo de la Patagonia es inagotable, porque la relación con la naturaleza es extremadamente potente desde el punto de vista de la activación de los sentidos. Por ello, recientemente aparecen otros imaginarios más elaborados, apoyados por principios filosóficos como el "biocentrismo" de Arne Naess (1990) ${ }^{12}$, instalan nuevos conceptos sobre el territorio, enriqueciéndolo semánticamente a partir del respeto a la vida y a la diferencia biológica. Este es el caso de Pumalín (puma verde en mapudungún), el primer parque privado conservacionista del Cono Sur, un santuario de la naturaleza y uno de los predios del ambientalista norteamericano Douglas Tompkins, propietario en Chile y Argentina de grandes extensiones de tierra y principal donante de algunas de ellas a estos países. La figura de Tompkins aparece, por una parte, como un contrasigno de la noción de empresario que maneja nuestra cultura, debido a que el éxito de toda empresa está en la máxima acumulación individual posible y él no lo realiza (Elizalde, 2002:77). Por otra, su concepto preservacionista de la "ecología profunda" le permite instalar entre los vecinos y los visitantes al parque un imaginario de prácticas de lo deseable y la posibilidad de desarrollar una autonomía administrativa sobre el territorio, es decir, tener reglamentaciones propias en sus 900.000 hectáreas de tierras adquiridas (Sánchez, 2009:71), promocionando el sentido de que en un pasado remoto, la naturaleza no estuvo subordinada, sino que los humanos eran parte de ella.

Así, Pumalín ${ }^{13}$, de más de 300.000 hectáreas, es filosóficamente un lugar de conservación de los bosques, donde se aprecian los últimos alerces de 3.000 años, en el que está prohibido cazar, pescar, encender fuego, derribar un árbol o arrancar una especie 


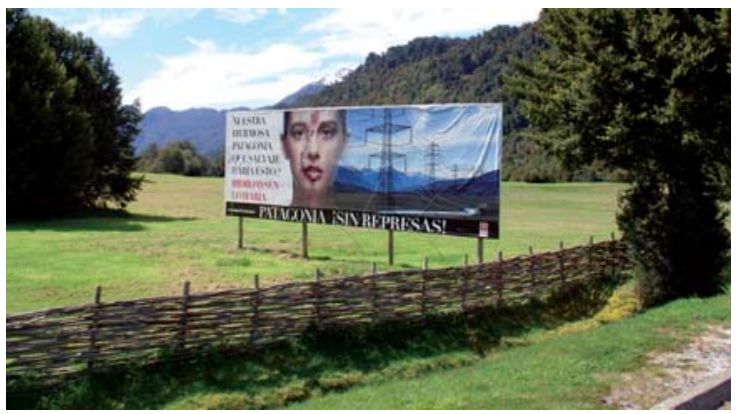

Figura 5. Patagonia sin represas. Entrada al sector El Amarillo, parte del proyecto ambientalista de Douglas Tompkins en Chaitén. Fotografía: autores. vegetal; los ríos, las aves, los peces y los animales circulan libremente, asegurando su futuro. El parque protege tierras vírgenes, biodiversidad, y se propone despertar la conciencia de la belleza y de la magia de la naturaleza.

Paralelamente, en la Patagonia se observan otros sueños y objetivos contrapuestos en el control del territorio que puede estar en la captura deportiva de una trucha de grandes proporciones o ser el material genético de la biota o del agua. En la terra australis es posible ser nuevamente no solo colono, sino pionero. Las miles de hectáreas compradas por multimillonarios extranjeros, dueños de imperios de la ropa, la televisión, los alimentos, equipos de fútbol, tales como los hermanos Benetton, Ward Lay, Ted Turner, Joseph Lewis, DiCaprio, Stallone, entre otros, les pueden permitir ser "el primer hombre" al poner un pie en lo virgen (Sánchez, 2009); son émulos de Orélie Antoine de Tounens, "rey de la Patagonia y la Araucanía"14, porque hay excentricidades o gustos que parecieran no tener límites cuando se llega al último refugio de la naturaleza. Sin embargo, también el sueño puede ser la apropiación de los glaciares, de los potenciales recursos farmacológicos, el agua milenaria para ser embotellada, el oxígeno, los minerales del subsuelo o el establecimiento de alguna colonia protegida con identidad religiosa.

Asimismo, en un proceso emergente, la Patagonia se renueva y configura también con hombres y mujeres que se avecinan por "cambio de estilo de vida"; renuncian a la modernidad y a la vida urbana; también para el migrante por amenidad es el punto de fuga del capitalismo y del Estado nacional, es un lugar para encontrarse consigo mismo y recuperar tiempo. Es una migración de quienes alguna vez fueron turistas y que deciden, a través de un proceso de activación de su memoria y vivencias, regresar para radicarse, para constituirse en uno más del lugar, de manera estacional o anual, en un proceso de valoración de atributos ambientales y culturales que la urbe no provee. Estos nuevos vecinos invierten en segundas viviendas o viviendas definitivas y también desarrollan microemprendimientos turísticos. En este sentido, la Patagonia es como la finis terrae de la experiencia humana (...) es fácil extraviarse físicamente, pero también es donde resulta más sencillo encontrarse con el yo salvaje, porque allí la vida es auténtica, plena o natural (Bohoslavsky, 2009:49-50).

\section{UN NUEVO VECINO QUE AMENAZA}

En esta diversificada inmersión de actores en la naturaleza, irrumpe el proyecto HidroAysén, una gran fuente de acumulación de agua para la generación de hidroelectricidad ubicada en las comunas de Cochrane, Tortel y O'Higgins. La obra proyectada corresponde al proyecto privado ${ }^{15}$ más emblemático de transformación territorial e implica la construcción de cinco represas para producir electricidad: dos se emplazarían en el río Baker, el más caudaloso del país, y tres en el río Pascua. Al concretarse la obra, se inundarían 5.900 hectáreas de reservas naturales, generaría un total de 2.750 megavatios (MW), con una producción anual de 18.430 gigavatio hora (GWh); todo lo cual implicaría la implementación de una línea de transmisión de más de 2.000 kilómetros, que cruza siete regiones, ya que su objetivo es abastecer a la capital y a la industria minera en el Desierto de Atacama.

Esta iniciativa, de gran magnitud e impacto comunicacional, social y ambiental, es coherente con los emprendimientos energéticos empresariales propios de un verdadero culto ingenieril como lo fueron Pangue y Ralco en la década del $90^{16}$, imponiéndose como norma lo colosal, ya que el tamaño es una protección contra las compras hostiles y un freno para competidores potenciales (Sohr, 2012:77). Es decir, la racionalidad económica -en el país más neoliberal-se impone por sobre otras consideraciones estratégicas; lo que revela que el espacio no debe considerarse únicamente como un objeto pasivo o simple soporte físico, sino como un agente activo y dinámico con influencia en las relaciones socioeconómicas (Caravaca, 1998:41), y que éste no es efectivamente "vacío".

La megaintervención se configura como un "desastre planificado", pues comienzan sus impactos en el proceso de elaboración del proyecto, en conjunto con los debates y conflictos que se generan en la interacción entre los distintos actores (Latta, 2011:113). Este se asocia a los enlaces e implementaciones contradictorias de estructuras de poder, compromisos sociales y valores culturales, lo que provoca alto estrés en la población. Según una encuesta realizada por el Centro de Encuestas del diario La Tercera, un 74\% rechaza la construcción de HidroAysén, un 83\% cree que de concretarse, el impacto será "mucho" o "bastante", el 68\% estima que el costo ambiental será más alto que el beneficio. HidroAysén genera una mayoritaria sensación de rechazo. No hay patrones de edad, estrato socioeconómico, ubicación geográfica (Santiago o regiones) o posición política en las que el proyecto sea aprobado por los encuestados (La Tercera 2011).

Entonces, hay temor por la modificación de los ecosistemas y trastorno de la economía local, un sentimiento de amenaza por la privatización del agua, por la pérdida del modo de vida y cultura tradicional, al aumento de los valores de las propiedades y los insumos y posible llegada de drogas, prostitución, población flotante y marginalidad (Latta, 2011:120).

Estos sentimientos y aprehensiones contradicen la búsqueda de la armonía y del encontrarse en un nuevo proyecto existencial como los señalados más arriba. La posible agresión a la naturaleza y al esfuerzo por reinventar(se) la vida en ella, es también lo que ha potenciado la marca territorial de la Patagonia, porque ésta conlleva un concepto que imprime, precisamente, una condición de lo que para muchos y en múltiples lugares hay que defender: Aysén, reserva de vida.

\section{CONCLUSIONES}

La complejidad de las contradicciones en la Patagonia se relaciona con los límites de la frontera austral de Chile, los imaginarios que visionan su destino y la posibilidad de que éstos puedan convivir, coexistir o excluirse; lo es sobre la noción de desarrollo, en términos económicos, ambientales, filosóficos, antropológicos y sociológicos. La producción de los lugares por el capitalismo tardío conduce necesariamente a la agregación de valor al territorio mediante la creación de nuevas imágenes, su organización simbólica y los 
discursos asociados. En este proceso se evidencia cómo se preservan, amenazan, defienden o destruyen los recursos naturales, los bienes culturales y los modos de vida locales. Al mismo tiempo, cómo se produce el control de los recursos, la distribución de los beneficios y el coste de las externalidades.

Este proceso no se da libre de conflictos, porque las comunidades locales reaccionan, filántropos compran tierras para conservación, grupos ambientalistas protegen la flora y la fauna, y denuncian las transformaciones sociales y territoriales; los actores concurren con lógicas distintas, que se combinan con intereses locales, regionales, nacionales y transnacionales. En esta reestructuración imaginaria y material del territorio, se identifican con mayor fuerza dos grandes narrativas que contienen orientaciones de desarrollo distintas: la del valor de uso y la del valor de cambio. La primera, le asigna el valor de uso, de conservación y contemplación al territorio, y trata de contener las megaintervenciones y sus transformaciones. La segunda, la del valor de cambio, sólo ve en éste la posibilidad de explotación de recursos naturales como el agua para transformarla en energía, cuyo destino estará a miles de kilómetros.

En las tres últimas décadas, debido a la fórmula extractivista del modelo económico neoliberal, donde el $50 \%$ de las exportaciones de Chile son cupríferas y alcanzan al $60 \%$ de recursos primarios (Solimano, 2012), el territorio se encuentra intervenido con ésta orientación, con fuerte presión por los recursos hídricos ante la falta de otras fuentes de energía nacionales. Además, las débiles políticas públicas de ordenamiento territorial y regional, de preservación, de cuidado del medioambiente y de conservación de la biodiversidad, han generado un conjunto de externalidades desde la zona norte hasta la VIII región del Bio-Bío. Estas experiencias no han servido como reflexión y aprendizaje por parte del Estado chileno para contrarrestar las recientes amenazas al territorio austral de la Patagonia, en la que aún quedan reservas de vida natural.

Entre las contradicciones, que por cierto tienen matices, aparece por una parte, el espacio desprovisto del habitar, siendo desvalorizado de sus cargas simbólicas y transformado sólo en un valor de cambio; y, por otra, aparece su valor de uso, el del habitar cotidiano y local, de la convivencia con los elementos, de la relación de sentido que las comunidades codifican como valor cultural, el de los imaginarios y las filosofías que lo recorren.

A pesar de que conflictos medioambientales de distinta envergadura se han vivido casi a lo largo de todo el país, el de HidroAysén se realza porque este territorio patagónico posee una carga semántica que constituye un gran activo, el que es de carácter internacional. Se trata de una naturaleza inviolada, escasamente intervenida y sustentable, aún salvaguarda del modelo extractivista que define a la economía del país. Toda formula contraria que frene la marcha infinita del modelo, como Pumalín, cuestiona la extraña simbiosis entre el liberalismo económico y el integrismo cultural y político que caracterizan al discurso hegemónico (Elizalde, 2002:77).

Pocos lugares y no muchos grupos y habitantes, de puntos aislados y abandonados, alcanzarán la adhesión respecto de sus demandas particulares, como está ocurriendo con la Patagonia y sus habitantes. Hay conciencia de que los patrones de vida y de comportamiento de las metrópolis y las grandes empresas, en general, son altamente demandantes de recursos naturales, pero, a la vez, extremadamente prodigiosos en residuos y desechos. La insostenibilidad del modelo a la luz de la contabilidad ambiental, vuelve el descontento en un tema planetario. En la Patagonia, lo que está en juego es el cambio, la transformación territorial y la cohesión social; cómo se forma o da curso a una nueva sociedad con la ruptura del aislamiento a cuestas y cómo se hacen sostenibles y sustentables comunidades con nuevas tensiones, porque el desarrollo lo es en relación al bien-estar de las personas, siendo esto, lo único que tiene sentido.

\section{BIBLIOGRAFÍA}

ALEUY Ó. (2012) Memorial de la Patagonia. Santiago: RIL Editores.

BANDIERI S. (2011) Historia de la Patagonia. Buenos Aires: Editorial Sudamericana.

BARABÁS A. (2004) La construcción de los etnoterritorios en las culturas indígenas de Oaxaca. Desacatos. Revista de Antropología Social 14:145-168.

BECK U. (1998) La sociedad del riesgo. Hacia una nueva modernidad. Barcelona: Paidós.

BOHOSLAVSKY E. (2009) El complot patagónico. Nación, conspiracionismo y violencia en el sur de Argentina y Chile (siglos XIX y XX). Buenos Aires: Prometeo.

BORRERO J. (2005) La Patagonia trágica. Asesinatos, piratería y esclavitud. Ushuaia, Argentina: Zagier \& Urruti.

BOISIER S. (2006) Imágenes en el espejo. Aportes a la discusión sobre crecimiento y desarrollo territorial. Santiago: Editorial Puerto de Palos.

BRUNSWIG DE BAMBER M. (2012) Allá en la Patagonia. La vida de una mujer en una tierra inhóspita. B de Bolsillo, Buenos Aires.

BYBEE R. (1991) Planet Earth in Crisis: How Schould Science Educators Respond? The American Biology Teacher 53, 3:146-153.

CARAVACA I. (1998) Los nuevos espacios emergentes. Estudios Regionales, 50:39-80.

CASTELLS M. (2006) Globalización, desarrollo y democracia: Chile en el contexto mundial. Santiago: Fondo de Cultura Económica.

CENTRO DE ENCUESTAS (2011) 74\% rechaza Hidroaysén. La Tercera, 15 de mayo.

CHATWIN B. (2004) En la Patagonia. Barcelona: Quinteto.

CHEYRE J. (2012) Entrevista Radio Universidad de Chile, 14 de marzo.

CRUTZEN P. (2002) Geology of mankind: the anthropocene. Nature 415:23.

DELEUZE G., GUATTARI F. (1977) Rizoma. España: Pre-textos.

DIMITRIU A. (2002) Producir y consumir lugares: Reflexiones sobre la Patagonia como mercancía. Revista de Economía Política de las Tecnologías de la Información y Comunicación. www. eptic.com.br (Recuperado el 15 de agosto de 2013).

ELIZALDE A. (2002) Parque Pumalín: aporte al desarrollo regional. En Parque Pumalín. Obstáculo u oportunidad para el desarrollo. Sara Larraín y Caroline Stevens (editoras), 77-83. Santiago Chile: LOM.

GARCÍA CANCLINI N. (1982) Las culturas populares en el capitalismo. Cuba: Ediciones Casa de las Américas.
100 > Revista Márgenes № 13 Vol. 10 > Diciembre 2013: 91-102 Facultad de Arquitectura > Universidad de Valparaíso
$>$ ISSN electrónico 0719-4436 $>$ ISSN impreso 0718-4034 
HORVARTH A. (2002) Parque Pumalín: perspectiva de desarrollo de la zona austral. Parque Pumalín. Obstáculo u oportunidad para el desarrollo. Sara Larraín y Caroline Stevens (editoras) 47-54. Santiago Chile: LOM.

HUDSON W. (1893) Idle days in Patagonia. New York: D Appleton and Company.

HUFFSCHMID A. (2012) Introducción. Topografías en conflicto. En Memorias, espacios y ciudades en disputa. Argentina: Nueva Trilce Editorial.

INSTITUTO NACIONAL DE ESTADÍSTICA (2013) Censo de Vivienda y Población. Santiago, Chile.

LAMING A. (2011) En la Patagonia confín del mundo. Temuco, Chile: Ofqui Editores.

LARRAÍN S. y STEVENS C. (editoras) (2002) Programa Chile Sustentable Parque Pumalín. Obstáculo u oportunidad para el desarrollo. Santiago Chile: LOM.

LARRAÍN J. (2001) Identidad chilena. Santiago Chile: LOM.

LATTA A. (2011) Los desastres planificados: megaproyectos y trauma socio-ambiental, el caso de HidroAysén. Sociedad Hoy 20:111-129.

MARCUSE H. (1993) El hombre unidimensional. Ensayo sobre la ideología de la sociedad industrial avanzada. Barcelona: Editorial Planeta.

MARTINIC M. (2001) La actividad industrial en Magallanes entre 1890 y mediados del siglo XX. Revista Historia 34:91-115.

NAESS A. (1990) Ecology, Community and Lifestile: Outline of an Ecosophy. Cambridge: Universe Press.

NOGUÉ J. (2006) La producción social y cultural del paisaje. En Mata, Rafael y Álex Tarroja (coords.), 135-143. El Paisaje y la gestión del territorio. Criterios paisajísticos en la ordenación del territorio y el urbanismo. Visiones, Diputació Barcelona, Colección territorio y gobierno.

NOUZEILLES G. (2002) El retorno de lo primitivo. Aventura y masculinidad. En La naturaleza es disputa. Retóricas del cuerpo y el paisaje en América Latina, Gabriela Nouzeilles (Comp.) Buenos Aires: Paidós.

OSORIO M. (2007) Aisén territorio y Aisén humanidad. Itinerario de una construcción social de la(s) Identidad(es) Regional(es). En Otras narrativas en Patagonia. Tres miradas antropológicas a la región de Aisén. Mauricio Osorio, Gonzalo Saavedra G. y Héctor Velásquez. Santiago: Ediciones Ñire Negro.

PATAGONIA INC. http://www.patagonia.com/us/commonthreads/? $\mathrm{In}=452$

PINE, J. and GILMORE J. (1999) The Experience Economy. Boston: Harvard Business School Press.

RODRÍGUEZ J. (2004) La reinvención del paraíso: sueño y olvido en los habitantes de los últimos pueblos salitreros del desierto de Atacama, Chile. En Desierto y fronteras. EI norte de México y otros contextos culturales. Hernán Salas y Rafael Pérez Taylor (editores), 123-152. México, D.F.: Universidad Nacional Autónoma de México, IIA-UNAM, Plaza y Valdés Editores.
SACHS J. (2008) Economía para un planeta abarrotado. Barcelona: Debate.

SÁNCHEZ G. (2009) La Patagonia vendida. Los nuevos dueños de la tierra. Buenos Aires: Marea Editorial.

SCHIWY F. (2002) Ecoturismo, indígenas y globalización. En La naturaleza en disputa. Retóricas del cuerpo y el paisaje en América Latina. Gabriela Nouzeilles (comp.). Buenos Aires: Paidós.

SOHR R. (2012) Chile a ciegas. La triste realidad de nuestro modelo energético. Chile: Ramdom House Mondadori.

SOLIMANO A. (2012) Capitalismo a la chilena. Y la prosperidad de las élites. Santiago: Catalonia.

SOUZA MARTINS J. (2009) Fronteira. A degradação do outro nos confins do humano. São Paulo: Editora Contexto.

STEFFEN W., CRUTZEN P. J., MCNEILL J. R. (2007) The Anthropocene: Are Humans Now Overwhelming the Great Forces of Nature? AMBIO 36, 8:614-621.

STONICH S. (1998) Political Ecology of Turism. Annals of Tourism Resarch 25, 1:25-54.

TORRES G. (2013) Capitalismo tardío, modernización y desarrollo sustentable. Revista Pacarina del Sur, 4. http://www.pacarinadelsur.com/home/utopias/127-capitalismo-tardiomodernizacion-y-desarrollo-sustentable (consultado el 12 de septiembre de 2012).

NOTAS

1 Este trabajo es parte del Proyecto Fondecyt 1120795 Etnografía de la colonización y recolonización de Chiloé Continental. Actores, intercambios y conflictos.

2 A los entrevistados se les ha garantizado el anonimato conforme a los protocolos de investigación.

3 En los estudios revisados no se encuentra una referencia precisa sobre cuál sería el extremo norte de la Patagonia Occidental, si el Seno de Reloncaví, Valdivia o Pucón. Esto debido a que la Patagonia no es una noción jurisdiccional, sino que es un amplio concepto que incluye geografía, población, valor agregado de marketing e imaginario.

4 Los datos del Censo de Vivienda y Población (2012), se encuentran en proceso de revisión técnica por parte del Instituto Nacional de Estadística (INE). Sin embargo, la variación intercensal frente a los resultados del año 2002, muestran una disminución de la población en las zonas rurales.

5 Particularmente es el caso de Chile.

6 La primera Constitución de Chile (1833) definió como límite sur de la Patagonia el Cabo de Hornos. Sin embargo, no es hasta el 1843 cuando se hace efectiva la presencia del Estado chileno, a través de la fundación del Fuerte Bulnes en las cercanías de la actual ciudad de Punta Arenas. Este constituye el primer asentamiento bajo dominio del Estado Chileno.

7 Las Oficinas constituyen emplazamientos industriales privados ubicados en medio del Desierto de Atacama, los que contaban con infraestructura propia para las faenas de elaboración de salitre, a lo que se sumaba un complejo habitacional para trabajadores solteros y algunas familias, y una pulpería que 
surtía de alimentos a la población. La diferencia con las company town, es que éstas últimas, también privadas, tenían una complejidad mayor en términos de servicios, ya que sumaban lugares para la recreación que generaban una autonomía (deporte, cine, teatro, bibliotecas), y que permitían elaborar un proyecto de vida conforme al trabajo garantizado, la asignación de vivienda y los servicios de alimentación. Ambas modalidades de asentamientos mineros, se encontraban vinculados a una red ferroviaria que conectaba con los puertos que permitían la exportación de salitre y la llegada de los productos necesarios para la manutención de trabajadores y familias en la zona interior (Rodríguez, 2004).

8 Hemos registrado en la zona más austral de la provincia de Palena y en la región de Aysén, que en los años 50 y 60, profesores eran instruidos por funcionarios del Ministerio de Educación y Carabineros para que en las escasas escuelas se cantara y bailara conforme a lo "huaso" de la zona central, para diferenciarse de las prácticas y vestimentas propias del "gaucho” argentino.

9 Las comillas representan registros de campo recogidos en la provincia de Palena y la región de Aysén.

10 Consciente de los problemas permanentes de conectividad, demográficos y de escasa oferta de empleabilidad, ya años antes el senador por la región de Aysén Antonio Horvarth (2002), en una mirada territorial de escala más que de gran intervención, intenta dar una respuesta al aislamiento y la falta de actividades productivas fijadoras de población. Identifica una agenda posible de desarrollo para la región, destacando las potencialidades del turismo, el bosque nativo, la acuicultura (de manera diferente como se ha realizado hacia el norte), y el aprovechamiento forestal (en áreas erosionadas), la producción limpia, natural y orgánica con sello de certificación en energía, industria y minería.

11 Los entrecomillados representan testimonios registrados en trabajos de campo.

12 Se plantea el principio de igualdad biocéntrica como eje de la llamada "ecología profunda". Esto significa que las cosas que se hacen no deben privilegiar al ser humano, sino que se deben hacer por todos los seres vivos. Por ello, se destrona la pirámide antropocéntrica y la figura se transforma en una tela de araña, donde los hombres y mujeres ocupan sólo un lugar en ella. Esta formulación es esencialmente crítica respecto de la concepción de desarrollo de Occidente, ya que los problemas ambientales son producto de una manifestación física de las formas de operar de nuestra sociedad y cultura.

13 Destacado en las noticias y la opinión pública como Santuario de la Naturaleza, tuvo en 2002 entre 8.000 y 10.000 visitantes. Sin embargo, también se le ubica en el mapa de los conflictos del "desarrollo" ya que impediría las actividades económicas como la hidroelectricidad, salmonicultura o minería (Larraín y Stevens 2002:9).

14 Autoproclamado en 1860.

15 Es propiedad de un consorcio controlado por Colbún y EndesaChile de la italiana ENEL, adjudicatarias de casi la totalidad de los derechos de agua chilenos.

16 Se trata de represas gigantescas de propiedad de Endesa, de costos de 340 y 463 millones de dólares, apoyadas por el
Banco Mundial, ubicadas en la cordillera en zona étnica pehuenche. La primera fue construida sin consultar a las comunidades y sin tomar en cuenta los impactos ambientales. En la segunda, hubo una oposición unánime de las comunidades Quepuca Ralco y Ralco Lepoy en el proceso de evaluación de impacto ambiental. Pese a ello, el Presidente de la República Eduardo Frei Ruiz-Tagle, manifestó públicamente su aprobación para la construcción de la hidroeléctrica. El resultado es considerado desastroso desde el punto de vista social y desde la perspectiva de los derechos humanos, ya que muchas familias debieron abandonar sus tierras desplazándose a zonas lejanas, sin posibilidad de retorno. 